\title{
Right Ventricular Outflow Tract Reconstruction with Bicuspid Valved Polytetrafluoroethylene Conduit
}

Running Head. Bicuspid valved PTFE conduit

Authors.

Masahiro Yoshida, MD'),

Peter D.Wearden, $M D, \mathrm{PhD}^{\prime}$ ),

Onur Dur, MS²),

Kerem Pekkan, $\mathrm{PhD}^{2)}$,

Victor O. Morell, MD')

1) Department of Cardiothoracic Surgery, Children's Hospital of Pittsburgh, Pittsburgh, PA, USA

2) Department of Biomedical Engineering, Carnegie Mellon University, Pittsburgh, PA, USA

Meeting Presentation.

Southern Thoracic Surgical Association, 56th Annual meeting, Marco Island, Florida Keywords.

Computer application, congenital heart disease, CHD Rastelli, Heart valve,

Pulmonary valve

Word Count. 2326

Corresponding Author.

Masahiro Yoshida, MD.

Department of Cardiothoracic Surgery, Children's Hospital of Pittsburgh, 45th Street \& Penn Avenue Pittsburgh, PA 1520I, USA

Tel; 4I2-692-52I8 Fax; 412-692-58I7

E-mail; masahiro.yoshida@chp.edu 


\section{Abstract}

Background: In general, all conduits available for right ventricular outflow tract (RVOT) reconstruction eventually become stenotic and/or insufficient. Due to the lack of an ideal conduit and with the hope of reducing the incidence of reoperations we have developed and utilized a bicuspid valved polytetrafluoroethylene conduit (PTFE) for the reconstruction of the RVOT. The purpose of this study was to review our early experience with this conduit.

Methods: Since October 2008 to September 2009, we have implanted bicuspid valved PTFE conduits in eighteen patients with a median age of 1.7 years (6 days-16 years). Their diagnoses include: Tetralogy of Fallot with pulmonary atresia in eight, truncus arteriosus in six, congenital aortic stenosis in two, transposition of great arteries in one and interrupted aortic arch with a ventricular septal defect in one. In sixteen patients, a complete biventricular repair was performed. In other two cases, the conduit was used for palliative right ventricular outflow reconstruction. The conduit sizes varied from 10 to $24 \mathrm{~mm}$ in diameter. Three-dimensional flow fields obtained from computational fluid dynamics studies are utilized in the conduit design process.

Results: There was no surgical mortality or reinterventions associated with the conduit placement in our series. At the time of discharge none of the patients had any echocardiographic findings consistent with significant conduit stenosis or insufficiency. During the follow-up period of $6.2 \pm 3.9$ months all patients were alive and only three had more than mild pulmonary insufficiency. Two of them were considered to be caused by catheter intervention for peripheral pulmonary stenosis.

Conclusions: Our bicuspid valved PTFE conduit has an acceptable early performance, with a low incidence of valve insufficiency and no conduit stenosis. Certainly, longer follow-up is necessary to fully assess its long-term benefits. 


\section{Text}

Based on general experience, all conduits available for right ventricular outflow tract (RVOT) reconstruction eventually become stenotic and/or insufficient because of calcificification especially in very young patients. 1) 2) 3) Due to the lack of an ideal conduit and with the hope of reducing the incidence of reoperations we have developed and utilized a bicuspid valved polytetrafluoroethylene (PTFE) conduit using standard stretch PTFE graft and 0.1mm-thick PTFE membrane (WL Gore \& Associates, Inc, Flagstaff, Ariz) for the reconstruction of the RVOT. The purpose of this study was to review our early experience with this conduit.

\section{Patients and Methods}

From October 2008 to September 2009, eighteen patients underwent implantation of a bicuspid valved PTFE conduits in the RVOT at Children's Hospital of Pittsburgh. The median age at the time of implantation was 1.7 years (range 6 days-16 years). Their diagnoses include: Tetralogy of Fallot with pulmonary atresia (TOF/PA) in eight, truncus arteriosus in six, congenital aortic stenosis in two, transposition of great arteries in one and interrupted aortic arch with a ventricular septal defect in one (Table 1). Thirteen patients had a previous procedure that included a palliative RVOT reconstruction in three, repair for truncus arteriosus in three, repair for tetralogy of Fallot in three, bilateral unifocalization in one, Ross procedure in one, arch reconstruction in one and arterial switch in one. Concomitant procedure at the time of conduit implantation included VSD closure in four, repair for truncus arteriosus in three, Ross procedure in one, reconstruction of the central pulmonary arteries in one, aortic valve replacement in one and one-stage repair of TOF/PA with unifocalizationonly in one. The diameter of conduit ranged from $10 \mathrm{~mm}$ to $24 \mathrm{~mm}$. The size of the conduit was determined according to the patients' body weight and body surface area (Figure 1). This research study was approved by our institutional review board. 


\section{Operative Technique}

The valved conduit was constructed in the operating theater at the time of surgery. First, the PTFE conduit is turned inside out, and then the two cusps created from $0.1 \mathrm{~mm}$ PTFE membrane are sutured to the inside wall of the conduit using a running 7-0 polypropylene running suture for conduits less than or equal $14 \mathrm{~mm}$ in diameter and 6-0 polypropylene for larger ones. Finally, the conduit is turned outside in (Figure 2). The shape and dimensions of the valve leaflets for each specific conduit diameter are shown in Figure 3. Note that the conduit has a small none-valved portion at the bottom, representing $15 \%$ of circumference of conduit. This allows for a minimal amount of regurgitation which should prevent thrumbus formation at the base of the valve sinuses. It has been our practice to place the "valved" portion of the conduit distally, leaving just a few millimeters of conduit wall beyond the top margin of PTFE cusps. The proximal end is then trimmed appropriately to match the opening in the RVOT.

\section{Post-Operative Anticoagulation}

Low dose aspirin (1-5 mg/kg/day) was started in the hospital and continued for six months.

\section{Echocardiographic Evaluation}

All patients had an intraoperative trans-esophageal echocardiogram prior to discharge and during followup. These studies were systematically reviewed to assess the presence of pulmonary regurgitation and to determine the mean valve gradient. The pulmonary regurgitation was classified as trivial (grade 1), mild (grade 2), moderate (grade 3) and severe (grade 4) according to features of the jet, assessed with pulsed flow Doppler and color Doppler. Conduit stenosis was assessed by measuring the peak velocity through the valve with continuous-wave Doppler technique. 


\section{Statistical Analysis}

Preoperative and postoperative data were retrospectively collected. Descriptive data for continuous variables are presented as means \pm SD or as medians with ranges; categorical variables are presented as relative frequencies. Surgical mortality was defined as death within 30 days of operation. Analysis was performed with JMP 8.01 for Macintosh (JMP, Cary, North Carolina).

\section{Results}

There was no surgical and late mortality nor events associated with the conduit placement at the mean follow-up of $6.2 \pm 3.9$ months. All patients were doing well without any need for conduit reinterventions.

Echocardiographic evaluation of the conduit was done intraoperatively [T1] $(\mathrm{n}=18)$, at the time of discharge [T2] $(\mathrm{n}=18)$ and during follow-up $(\mathrm{n}=11)$. Echocardiography showed the presence of one, trivial or mild insufficiency in $17(94 \%)$ at T1, $17(94 \%)$ at T2 and $8(73 \%)$ at T3. There was only one patient who had moderate insufficiency in the operating theater and at discharge. It was a neonate who underwent repair of truncus arteriosus with a $12 \mathrm{~mm}$ conduit. We believe that the insufficiency was related to his relatively high heart rate, which prevented adequate valve function. In his latest echocardiogram there is only mild insufficiency at a lower heart rate.

During follow-up examination in eleven patients there was moderate insufficiency in three. Two of them, developed moderate insufficiency after undergoing catheter balloon angioplasty for peripheral pulmonary stenosis which could have damaged the PTFE valve. In remaining one case, the echocardiogram showed that one of valve leaflets was stuck in the open position. Pressure gradient across the conduit was $9 \pm 8 \mathrm{mmHg}$ at T1, $13 \pm 8$ at T2 and $19 \pm 15$ at T3 (Figure 4). During follow-up only one patient, a neonatal repair, had a pressure gradient greater than $30 \mathrm{mmHg}$ twelve months after surgery, related to rapid somatic growth. 


\section{Comment}

Right ventricular outflow tract reconstruction has been performed utilizing different types of conduits, most commonly aortic or pulmonary homografts, which have been associated with a high incidence of stenosis and/ or insufficiency requiring reoperations especially in very young patients 1), 2), 3). Also, exposure to homograft material has been proven to result in significant allosensitization, which could negatively affects the results of future cardiac transplantation.

Over the last couple of years we have opted to preferentially utilize a PTFE bicuspid valve conduit for RVOTR with the expectation that they will have a better overall performance than other conduits. Brown and collegues reported excellent long-term results using a PTFE monocuspid valve in the RVOT ${ }^{4)}$. Also, Ando and Takahashi described good long-term results of RVOT reconstruction using PTFE trileaflet valved conduit ${ }^{5)}$.

Our conduit was design with a bicuspid valve instead of a trileaflet valve because of one of the author's prior experience with a trileaflet conduit in which the "posterior" leaflet did not open (figure 5) during systole in two consecutive patients. It was theorized that the flow along the lesser curvature of the conduit was not sufficient to open the posterior leaflet and that is why we modified the valve component of the conduit to be bileaflet with a small posterior "non-valve" segment. The non-valve segment only represents $15 \%$ of the valve circumference, resulting in very little regurgitation.

In order to further investigate the general 3D flow patterns inside curved conduit and quantify fluid-induced forces important for valve kinematics, computational fluid dynamics (CFD) studies were performed. Pulsatile blood flow was simulated inside the curved RVOT conduit using the 2nd order 
accurate CFD solver (FLUENT 6.3.26. ANSYS Inc., Canonsburg, PA) which was priginally developed for investigating the reconstructive surgeries for single ventricle palliation ${ }^{6}{ }^{7)}$. Two conduits of $14 \mathrm{~mm}$ and $22 \mathrm{~mm}$ diameter were evaluated based on the BSA: $0.5 \mathrm{~m} 2$ and $1.35 \mathrm{~m} 2$ and the corresponding cardiac outputs: $1.2 \mathrm{~L} / \mathrm{min}$ and $2.4 \mathrm{~L} / \mathrm{min}$, respectively. Blood was chosen as Newtonian fluid with a viscosity of $3.71 \mathrm{e}-3 \mathrm{~N}-\mathrm{s} / \mathrm{m} 2$ and a density of $1060 \mathrm{~kg} /$ m3. Physiological RVOT flow waveform and blunt flow profile (typical for ventricle) was assigned at the inlet of the conduit in agreement with the clinical measurements. Computational domain of each conduit were discretized using 50,000 tetrahedral elements. According to our simulations, about one diameter distal from the inlet, blood flow skewed towards the major curvature of the conduit. Hence, the flow velocity at the lesser curvature of conduit was slower than that at the major curvature. Furthermore, flow profile was almost symmetrical along the curvature axis which indicates balanced the opening-forces exerted on each leaflet during the systole (Figure 6). These results perfectly agree with author's clinical experience in operating room. Similar bioengineering studies towards improved designs are ongoing.

Yamagishi and asssociates reported a very unique PTFE valved conduit design in $2007^{8)}$. It incorporated bulging sinuses that can generate diastolic vortex flow between the conduit wall and the leaflets, and hence potentially provide better long-term result than a conduit without sinuses. Future modification to our bicuspid valved conduit may include the creation of sinuses. Our ongoing CFD investigation will identify the benefit of sinus geometry on the RVOT conduit hemodynamics and guide its clinical implementation.

Our bicuspid valved PTFE conduit has an acceptable early performance with a low incidence of valve insufficiency and no conduit stenosis. The lack of allosensitization is another benefit of this conduit as well as possibly providing a reliable target to deliver percutaneously implantable valves. Certainly, longer follow-up is necessary to fully assess its long-term benefits. 


\section{References:}

1) Kaza AK, Lim HG, Dibardino DJ, Del Nido PJ, Mayer Jr. JE, Pigula FA. Long-term results of right ventricular outflow tract reconstruction in neonatal cardiac surgery: Options and outcomes, J Thorac Cardiovasc Surg 2009; 138: 911-6.

2) Schreiber C, Sassen S, Kostolny M, et al. Early Graft Failure of SmallSized Porcine-Valved Conduits in Reconstruction of the Right Ventricular Outflow Tract. Ann Thorac Surg 2006; 82: 179-86.

3) Shebani SO, McGuirk S, William J. Brawn, et al. Right ventricular outflow tract reconstruction using Contegra1 valved conduit: natural history and conduit performance under pressure. Eur J Cardio-thorac Surg 2006; 29: 397-405.

4) Brown JW, Ruzmetov M, Vijay P, Rodefeld MD, Turrentine MW. Right ventricular outflow tract reconstruction with a polytetrafluoroethylene monocusp valve: a twelve-year experience. J Thorac Cardiovasc Surg 2007; 133:1336-43.

5) Ando M, Takahashi Y. Ten-year experience with handmade trileaflet polytetrafluoroethylene valved conduit used for pulmonary reconstruction. J Thorac Cardiovasc Surg 2009;137:124-31 .

6) Pekkan K, Kitajima HD, Yoganathan AP, et al. Total cavopulmonary connection flow with functional left pulmonary artery stenosis: angioplasty and fenestration in vitro. Circulation 2005; 112: 3264-71.

7) Wang C, Pekkan K, Yoganathan AP, et al. Progress in the CFD modeling of flow instabilities in anatomical total cavopulmonary connections. Ann Biomed Eng, 2007; 35: 1840-56.

8) Miyazaki T, Yamagishi M, Kado H, et al. Expanded polytetrafluoroethylene valved conduit and patch with bulging sinuses in right ventricular outflow tract reconstruction. J Thorac Cardiovasc Surg 2007; 134: 327-3. 
Table 1. Patient profile

\begin{tabular}{lcc}
\hline Age & $1.7 \pm 1.5$ (years) & 6 days - 16 years \\
Body Weight & $20 \pm 19(\mathrm{~kg})$ & $3.4-67 \mathrm{~kg}$ \\
\hline Diagnosis & Tetralogy of Fallot & 8 \\
& Truncus Arteriosus & 6 \\
& Congenital AS (Ross) & 2 \\
& TGA & 1 \\
& IAA with VSD & 1 \\
\hline
\end{tabular}

AS; aortic stenosis, TGA; transposition of great arteries

IAA; interrupted aortic arch, VSD; ventricular septal defect 


\section{Figure Legends:}

Figure I.

We have various size of conduit from 10 to $24 \mathrm{~mm}$ in diameter. This graft shows correlation between conduit size and body surface area. The curved line shows normal pulmonary valve size by Rawlatt.

\section{Figure 2.}

Drawings of the steps to make bicuspid valved conduit. At first, a PTFE conduit with standard stretch wall is turned inside out. After holding the graft at both ends using Kelly's clamps, two cusps trimmed from PTFE sheet with $0.1 \mathrm{~mm}$ thickness using 6-0 or 7-0 polypropylene sutures. Actually author put the top of triangle first and put marking stitches at the middle of both sides. Then continuous suture is put using the stitch of the top. After completion of suturing two cusps, the conduit is turned back outside in (the upper drawings). The special feature of this conduit is having non-valved portion at the bottom (the lower drawings).

\section{Figure 3.}

The design of each valve. Each figures are following.

Circumference $(\mathrm{C})=$ Conduit size $\times 3.14$

Non-valved portion $(\mathrm{nV})=\mathrm{C} \times 0.15$

Width of Sinus $(\mathrm{WS})=(\mathrm{C}-\mathrm{nV}) / 2$

Height of Sinus (HS) $=\mathrm{WS} \times 0.7$

Width of Cusp $($ WC) $=$ WS $\times 1.2$

Height of Cusp $(\mathrm{HC})=\mathrm{HS} \times 0.9$

Fan of Cusp $(\mathrm{FC})=\mathrm{HC} \times 0.2$ 


\section{Figure 4.}

Pressure gradients of conduit at operation theater, at discharge and at clinic by echoacardiography.

\section{Figure 5.}

Echocardiography author experienced in Kobe, Japan. Stuck valve at the bottom of tricuspid valved conduit is shown $(\Delta)$. It was considered that flow velocity at the lesser curvature of curved conduit was slower than at the major curvature.

Figure 6.

Newtonian pulsatile blood flow simulated inside the $14 \mathrm{~mm}$ conduit for a cardiac output of 1.2LPM using 2nd order CFD solver (Fluent 6.3.6). Time-averaged velocity contours shown during systole indicated lower velocity at the lesser curvature of the conduit. 